\title{
Vestibulocochlear Nerve Neoplasm
}

National Cancer Institute

\section{Source}

National Cancer Institute. Vestibulocochlear Nerve Neoplasm. NCI Thesaurus. Code C5120.

Benign and malignant neoplasms which arise from the eighth cranial nerve, also referred to as the vestibulocochlear nerve. Clinical features may include hearing loss, vertigo, tinnitus, headache and involvement of the trigeminal or facial nerves. 